\title{
Sleep Characteristics and Behavioral Problems Among Children of Alcoholics and Controls
}

\author{
Maria M. Wong (iD), Kirk J. Brower, Deirdre A. Conroy, Kathryn A. Lachance, and \\ Elizabeth A. Craun
}

\begin{abstract}
Background: Past research has indicated that both sleep difficulties and a parental history of alcoholism increase the risk of behavioral problems. But it is not known whether sleep difficulties differentially increase the risk of problem behaviors among children of alcoholics (COAs) and controls. We compared multiple measures of sleep and the relationships between sleep and behavioral problems in these 2 groups of children.

Methods: One hundred and fifteen children aged 8 to $12\left(67 \%\right.$ COAs; $56 \%$ girls; $M_{\text {age }}=10.85$, $\left.\mathrm{SD}_{\text {age }}=1.51\right)$ participated in this study. Data presented here were taken from Time 1 of a larger prospective study designed to understand the relationship between sleep and alcohol use. All participants were naïve to alcohol and other illicit drugs. Participants were asked to wear an actigraph watch on their nondominant wrist for 1 week. Parents completed the Pediatric Sleep Questionnaire and the Achenbach Child Behavior Checklist.

Results: Parents of COAs were more likely to rate their children as overtired compared with parents of non-COAs. Structural equation modeling analyses focusing on overall internalizing and externalizing problems did not reveal any group differences on the relationships between sleep measures and behavioral problems. Regression analyses focusing on specific behavioral problems showed that longer total sleep time, parental ratings of "sleep more" and "sleep less" than other children interacted with COA status to predict specific behavioral problems.

Conclusions: Sleep difficulties and duration appear to be a general risk factor for behavioral problems in both COAs and non-COAs, yet the relationships between specific sleep parameters and behavioral problems appear to be different between the 2 groups.
\end{abstract}

Key Words: Sleep, Behavioral Problems, Children of Alcoholics, Childhood, Adolescence.

B EHAVIORAL PROBLEMS ARE an important developmental outcome to consider in childhood because these problems predict adult psychopathology, including alcohol use disorders (AUD) (Hussong et al., 2011; Zucker, 2006). Past research has indicated that both sleep difficulties (Gregory and Sadeh, 2012) and a parental history of alcoholism (Zucker, 2006) increase the risk of behavioral problems. Even though several studies reported that children of biological, alcohol-dependent parents (COAs) had more internalizing (Eiden et al., 2009; Hussong et al., 2008b) and externalizing problems than non-COAs (Eiden et al., 2007; Meyers et al., 2014), the factors responsible for these differences remain unclear. These factors may explain why some COAs are particularly at risk for behavioral problems. In this study, we examined whether sleep parameters might be related to the manifestation and severity of behavioral problems among COAs and matched controls.

From the Department of Psychology (MMW, KL, EAC), Idaho State University, Pocatello, Idaho; and Department of Psychiatry (KJB, DAC), University of Michigan, Ann Arbor, Michigan.

Received for publication July 19, 2017; accepted December 11, 2017.

Reprint requests: Maria M. Wong, PhD, Department of Psychology, Idaho State University, Pocatello, ID 83209-8112; Tel.: 208-282-2752; Fax: 208-282-4832; E-mail: wongmari@isu.edu

Copyright (C) 2017 by the Research Society on Alcoholism.

DOI: 10.1111/acer.13585
Studies comparing sleep parameters between COAs and non-COAs show inconsistent findings (Conroy et al., 2015; Wong et al., 2010). In prospective studies using sleep measures based on maternal ratings, there were no differences in the prevalence rates of sleep problems among COAs compared with controls (Wong et al., 2004, 2009, 2010). However, studies using actigraphy and polysomnography (PSG) have found differences in the sleep patterns and physiology of COAs compared with controls. One study compared actigraphy and sleep diary data between the 2 groups $(N=92,68$ COAs $)$. Actigraph data showed that COAs had slightly but significantly shorter total sleep time (TST) and more nighttime motor activity compared with controls (Conroy et al., 2015). Another study found that COAs had shorter TST, went to bed later, and spent less time in bed on weekends compared with controls ( $N=82,65$ COAs) (Hairston et al., 2016). In PSG studies, no differences in TST were found (Tarokh and Carskadon, 2010; Tarokh et al., 2012). The current study adds to the existing literature by comparing COAs and non-COAs on multiple objective and subjective sleep measures.

The relationships between sleep difficulties and behavioral problems have been reported in both nonclinical and clinical samples of children and adolescents (Gregory and Sadeh, 2012). Among a group of children living with adoptive and nonadoptive families, total sleep problem scores, as measured by parental ratings in the Child 
Behavior Checklist (CBCL) at age 4, predicted behavioral (e.g., aggression, attention problems) and emotional problems (e.g., anxiety/depression) in early adolescence $(N=490)$ (Gregory and O'Connor, 2002). In a large epidemiological study of Finnish children $(N=1,714)$, parental ratings of presence of sleep problems were the strongest background variables associated with parental ratings of emotional problems and negative mood (Maasalo et al., 2016). In a study of 135 healthy Israeli children, fragmented sleep measured by actigraphy predicted lower neurobehavioral functioning (i.e., more commission errors on the continuous performance test) and higher parental ratings of delinquent behavior, thought disorder, and total behavioral problems (Sadeh et al., 2002).

Studies of COAs also reported relationships between sleep measures and behavioral problems. In 1 study of boys $(N=257)$, maternal ratings of sleep difficulties and overtiredness in early childhood predicted attention and depression/anxiety problems in early adolescence for both male COAs and controls (Wong et al., 2004). Another study including both boys and girls found that maternal ratings of sleep difficulties and overtiredness at ages 3 to 8 predicted the development of internalizing and externalizing problems at ages 8 to $17(N=384)$ (Wong et al., 2009). In both studies, COAs did not differ from controls on any sleep measures or behavioral problems.

However, previous research did not examine whether the relationships between sleep measures and behavioral problems were the same for COAs and controls. Moreover, with the exception of a few studies carried out on non-COAs (Moore et al., 2009; Sadeh et al., 2002), most research used subjective measures such as parental ratings to assess sleep. Seldom did researchers use more than 1 sleep measure in the same study. Here, we present crosssectional data on the association between multiple sleep measures and behavioral problems among children with and without a parental history of alcoholism. We examined whether they differ on multiple sleep measures and the extent to which sleep played a differential role in behavioral problems among them. We hypothesized that COAs and non-COAs would be similar on sleep measures, but COAs would be higher on behavioral problems than non-COAs. We further hypothesized that sleep measures would have a stronger relationship with behavioral problems in COAs compared with non-COAs.

\section{MATERIALS AND METHODS}

\section{Participants}

One hundred and fifteen children aged 8 to 12 (67\% COAs; $56 \%$ girls; $\left.M_{\text {age }}=10.85, \mathrm{SD}_{\text {age }}=1.51\right)$ participated in a study designed to understand the longitudinal relationship between sleep characteristics and substance use. Data collection is still ongoing. All data presented here were from Time 1, when all children were naïve to alcohol and other drugs; $76 \%$ of participants were Caucasian, $11 \%$ were Hispanics, and $12 \%$ were from other ethnic groups (i.e., African American, Asian, Native American, or biracial).
COAs and their biological parents were recruited through local addiction treatment facilities, Alcoholics Anonymous meetings, community flyers, and advertisements in local newspapers, radio stations, and Facebook. Some parents of COAs were either undergoing treatment or had recently gone through treatment. Non-COAs (controls) and their biological parents were recruited via the same community flyers and advertisements. Non-COAs were matched with COAs on age, gender, and family income. All participants and their parents received payment to compensate for their time and effort spent. Children with the following characteristics were excluded from the study: (i) significant medical problems that may affect sleep (e.g., endocrine disorders, chronic pain, asthma); (ii) currently taking medications (nonpsychiatric or psychiatric) that affect sleep; (iii) DSM-IV Axis I disorder as indicated by the child and adolescent version of the Mini-International Neuropsychiatric Interview (MINI-KID) (Sheehan et al., 2010); (iv) evidence of a primary sleep disorder other than insomnia (e.g., obstructive sleep apnea); and (v) evidence of fetal alcohol syndrome (FAS) and fetal alcohol effects (FAEs). Children with the following characteristics were included: (i) between the ages of 8 and 12; (ii) able and willing to provide informed assent (child) and consent (parent); (iii) among COAs, at least 1 biological parent had a current or past history of alcohol abuse or dependence, that is, a score of $\geq 6$ on the Michigan Alcohol Screening Test (MAST) (Selzer, 1971) and/or a lifetime AUD (American Psychiatric Association, 2000) according to the MINIInternational Neuropsychiatric Interview (Sheehan et al., 1998); among non-COAs, neither biological parent had a lifetime history of alcohol abuse or dependence.

\section{Procedures}

Data for this study were collected in 2 different sessions. Research associates were blind to the COA status of the participants. During the screening interview (Session 1), both the participating parent and the child were administered the MINI. Parents filled out the MAST and completed the MINI AUD questions on themselves and the other biological parent. Parents also completed a demographics questionnaire.

During Session 2, a nurse practitioner did a physical examination and checked facial features of study participants. Screening of FAS, FAE, and other physical problems pertaining to the exclusion criteria was completed by the nurse, using information from this evaluation and the parents' self-report of drinking habits/patterns of the biological mother during pregnancy. Parents and children were asked to answer several questionnaires on sleep and behavioral problems during this session. Children were also given an actigraph and a sleep diary to complete for 1 week.

\section{Sleep Measures}

Actigraphy. Participants were asked to wear an actigraph watch on their nondominant wrist for 1 week, except when they took a shower, bathed, or swam. They were instructed to maintain their normal sleep schedule and filled out a simple sleep diary. The diary asked questions about bedtime, rise time, amount of time it took to fall asleep, and quality of sleep. The actigraphs (Actiwatch- $\mathrm{L}^{\mathrm{TM}}$, Mini-Mitter; Phillips Respironics, Bend, OR) electronically measure the number of movements that exceed $0.01 \mathrm{~g}$ (gravitational force) per minute of recording. In addition, a photoconductive cell records light level exposure, measured in lux. Data were collected in 1-minute epochs. Trained personnel coded the data for sleep and wake times according to activity level, light exposure, and signals as indicated by participants when they were ready to go to bed and when they woke up. Inter-rater agreement ranged from 85 to $90 \%$. Four sleep variables were derived from these data and averaged across the 
week: TST, sleep efficiency (SE; \% time asleep/total time in bed), sleep onset latency (SOL; time required to fall asleep), and wake time after sleep onset (WASO). The reliability and validity of actigraphy measures have been demonstrated in previous studies (Acebo et al., 1999; Ancoli-Israel et al., 2003; Sadeh, 2015).

Parental Ratings. Parental ratings of their children's sleep problems and issues were measured by the Pediatric Sleep Questionnaire (PSQ) (Chervin et al., 2000) and the CBCL (Achenbach, 1991). The PSQ is a well-established instrument measuring children's sleep difficulties, sleepiness, sleep-disordered breathing, and snoring. Parents responded "yes," "no," or "don't know" to items concerning their children's sleep habits and behaviors. Our analyses focused on sleep difficulties (3 items), daytime sleepiness (6 items), and sleep rhythmicity $(2$ items $)$. Responses were coded dichotomously $(0=$ no; $1=$ yes) for all items. The presence of sleep difficulties, daytime sleepiness, and sleep rhythmicity was computed based on a response of "yes" to any item related to each variable. Examples of sleep difficulties items include, "Does your child...have difficulty falling asleep at night? .. . have trouble falling back asleep if he or she wakes up at night?" "... .wake up early in the morning and have difficulty going back to sleep?" Examples of daytime sleepiness items include, "Does your child ... have a problem with sleepiness during the day? ...complain that he or she feels sleepy during the day?" Examples of sleep rhythmicity items include, "Does the time at which your child ...goes to bed change a lot from day to day?...or gets up from bed change a lot from day to day?"

The CBCL is a widely used instrument that measures common behavioral problems in the past 6 months. Five items were used to indicate sleep problems: "trouble sleeping," "overtired without good reason," "nightmares," "sleeps less than most kids," and "sleeps more than most kids during day and/or night." Responses to each item were scored on a 3 -point rating scale $(0=$ not true; $1=$ somewhat or sometimes true; 2 = very true or often true). A relatively small percentage of the sample had a score of 2 on the sleep items (i.e., trouble sleeping: $7.1 \%$; overtiredness: $2.7 \%$; nightmares: $4.4 \%$; sleeps less than most kids: $4.4 \%$; sleeps more than most kids: $0.9 \%$ ). Therefore, each item was recoded as a dichotomous variable $(0=$ not true, $1=$ sometimes or often true $)$.

\section{Behavioral Problems}

Parental ratings of behavioral problems were measured by the CBCL. We examined both internalizing (anxious depressed, withdrawn depressed, and somatization) and externalizing problems (rule-breaking behavior, aggression, and impulsivity) (Achenbach, 1991; Meldrum et al., 2012). These problems have been shown to occur more frequently among COAs compared with non-COAs (Zucker, 2006; Zucker et al., 2011). Responses were given on a 3point rating scale $(0=$ not true; $1=$ somewhat or sometimes true; $2=$ very true or often true). Mean scores on each problem were calculated. To ensure the independence between sleep measures and behavioral problems, no sleep items were used in the calculation. The Cronbach's alphas of each problem were $0.77,0.79,0.71,0.74$, 0.90 , and 0.87 for anxious depressed, withdrawn depressed, somatization, rule-breaking behavior, aggression, and impulsivity, respectively.

\section{Parental Alcohol Problems}

Children with at least 1 parent who had a score of $\geq 6$ on the MAST (Selzer, 1971) and/or who had a lifetime AUD according to the MINI (Sheehan et al., 1997, 1998) were considered to have a positive parental history of alcohol problems $(0=$ non-COA; $1=\mathrm{COA})$. One parent from each family participated in the study. Participating parents answered the MAST and completed the MINI AUD questions for both themselves and the other biological parent.
Partners/spouses have been demonstrated to be reliable informants of their partners' drinking (Rychtarik and McGillicuddy, 2005; Thomas et al., 1986). MAST scores have been shown to be correlated with alcoholism diagnoses (Selzer and Barton, 1977; Selzer et al., 1971).

\section{Analytic Plan}

The goals of the study were to examine the relationships between sleep variables and behavioral problems and to test whether the relationships were different for COAs and controls. Prior to the analyses, we examined the consistencies of different sleep measures. Data were analyzed by multiple regression (when the outcomes were continuous), logistic regression (when the outcomes were dichotomous), and structural equation modeling $(\mathrm{SEM})$. Gender $(0=$ male, $1=$ female $)$, age, and ethnicity $(0=$ non-Caucasian, $1=$ Caucasian $)$ were used as covariates if they had a significant relationship with the outcomes. Demographic variables were dropped if they were not significantly related to the outcome. In all analyses, sleep measures were predictors and different behavioral problems were outcomes. Potential group differences among COAs and controls were tested first in multiple regression models by creating interaction terms between COA status and predictors. A significant interaction term indicates that relationships between sleep and behavioral problems are different for the 2 groups.

In SEM, we used sleep and behavioral problem measures to estimate latent variables and examined the relationships among the latent variables. The main advantages of using this method lie in the possibility of simultaneously estimating relations among multiple observed and latent (unobserved) predictors and outcomes, thus lowering type I error. Model fit was evaluated by the chi-square goodness-of-fit test and 3 fit indices-Comparative Fit Index (CFI; Bentler, 1990), Tucker-Lewis Index (TLI; Tucker and Lewis, 1973), and root mean square error of approximation (RMSEA; Steiger \& Lind, 1980). The chi-square statistic evaluates the difference between the data and the fitted covariance matrices, that is, the hypothetical model (Bentler and Bonett, 1980). An insignificant value indicates a good fit. However, the chi-square test becomes overly conservative when sample size increases (Bentler, 1990). Therefore, other indices are also used to evaluate model fit. A value of 0.9 or above on fit indices such as the CFI and TLI indicates a good fit, whereas a value of 0.95 above indicates an excellent fit ( $\mathrm{Hu}$ and Bentler, 1999). Values of 0.06 or below on the RMSEA indicate a satisfactory fit (Hu and Bentler, 1999).

\section{RESULTS}

\section{Descriptive Statistics}

Table 1 presents descriptive statistics of all variables, separately for COAs and non-COAs and for the whole sample. Hypothesis 1 was partially supported. As expected, COAs did not differ from non-COAs on most sleep measures with the exception of 1 item. A higher percentage of COAs were rated by their parents as overtired compared with non-COAs $(\mathrm{OR}=9.21, p<0.05)$. Contrary to our expectation, COAs did not differ from non-COAs on any behavioral problems.

\section{Multiple Regression Analyses}

Relationships Among Different Sleep Measures. We examined the relationships between objective (actigraphy) and subjective sleep measures (parental ratings and youth 
Table 1. Means (SDs) of Sleep Measures and Behavioral Problems

\begin{tabular}{|c|c|c|c|}
\hline & Non-COAs & COAs & Total \\
\hline \multicolumn{4}{|l|}{ Sleep measures } \\
\hline \multicolumn{4}{|l|}{ Actigraphy } \\
\hline $\begin{array}{l}\text { Total sleep } \\
\text { time }\end{array}$ & $451.35(34.01)$ & 446.36 (52.22) & $448.25(48.03)$ \\
\hline $\begin{array}{l}\text { Sleep onset } \\
\text { latency }\end{array}$ & $37.74(37.40)$ & $37.95(30.04)$ & $37.65(32.50)$ \\
\hline Sleep efficiency (\%) & 76.69 (5.23) & $76.89(12.01)$ & $77.87(10.24)$ \\
\hline $\begin{array}{l}\text { Wake time after } \\
\text { onset }\end{array}$ & $53.27(15.38)$ & $56.69(19.57)$ & $55.60(18.19)$ \\
\hline \multicolumn{4}{|c|}{ Pediatric Sleep Questionnaire (parental) } \\
\hline Sleep difficulties (\%) & 36.8 & 44.7 & 42.1 \\
\hline Sleepiness (\%) & 36.8 & 46.1 & 43.0 \\
\hline \multicolumn{4}{|c|}{ Child Behavior Checklist (parental) } \\
\hline Nightmare (\%) & 30.6 & 32.4 & 31.8 \\
\hline Overtired (\%) & $2.8^{\mathrm{a}}$ & $16.9^{\mathrm{a}}$ & 12.1 \\
\hline $\begin{array}{l}\text { Sleeps less than } \\
\text { most kids (\%) }\end{array}$ & 13.9 & 22.2 & 19.4 \\
\hline $\begin{array}{l}\text { Sleeps more than } \\
\text { most kids (\%) }\end{array}$ & 8.3 & 8.3 & 8.3 \\
\hline $\begin{array}{l}\text { Having trouble } \\
\text { sleeping (\%) }\end{array}$ & 25.0 & 28.2 & 27.1 \\
\hline \multicolumn{4}{|l|}{ Behavioral problems } \\
\hline \multicolumn{4}{|l|}{ Internalizing problems } \\
\hline Anxious depressed & $3.65(3.31)$ & $4.06(3.47)$ & $3.97(3.34)$ \\
\hline $\begin{array}{l}\text { Withdrawn } \\
\text { depressed }\end{array}$ & $2.33(2.33)$ & $1.75(2.65)$ & $1.94(2.50)$ \\
\hline Somatization & $2.31(2.16)$ & $2.12(2.39)$ & $2.17(2.29)$ \\
\hline \multicolumn{4}{|l|}{ Externalizing problems } \\
\hline $\begin{array}{l}\text { Rule-breaking } \\
\text { behaviors }\end{array}$ & $0.83(1.08)$ & $1.79(2.55)$ & $1.53(2.23)$ \\
\hline Aggression & $4.86(4.31)$ & $5.86(6.06)$ & $5.64(5.48)$ \\
\hline Impulsivity & $4.25(3.36)$ & $5.76(5.71)$ & $5.34(4.99)$ \\
\hline
\end{tabular}

All analyses controlled for gender, age, and ethnicity.

${ }^{\mathrm{a}}$ Comparisons between the 2 groups were significant at $p<0.05$.

report). Parental ratings of sleep difficulties in the PSQ significantly predicted longer SOL $(b=20.95(6.07), p<0.01)$ and lower SE $(b=-5.15(1.94), p<0.01)$. Sleepiness ratings in the PSQ also predicted longer SOL $(b=12.52(6.18)$, $p<0.05)$ and lower SE $(b=-4.46(1.96), p<0.05)$. CBCL parental ratings of "having trouble sleeping" significantly predicted lower TST $(b=-35.94(10.27), p<0.01)$ and longer SOL $(b=17.08(7.25), p<0.05)$. Moreover, parental ratings of "sleeps less than most kids" in the CBCL predicted shorter TST $(b=-35.98(11.68), p<0.01)$.

Relationships Between Sleep Measures and Behavioral Problems. All behavioral problems were positively skewed -more participants clustered around lower rather than higher scores. Therefore, they were subject to a log transformation. Multiple regression analyses showed that hypothesis 2 was partially supported. As shown in Table 2, the relationships between sleep parameters and internalizing problems were mostly the same for COAs and non-COAs (i.e., most interaction terms were insignificant). There were a few exceptions. Among both COAs and non-COAs, having nightmares was significantly associated with being anxious depressed. However, the association was stronger among non-COAs $(b=0.46(0.11), p<0.001)$ than COAs $(b=0.17$
Table 2. Relations Among Sleep Measures, Children of Alcoholics (COA) Status, and Internalizing Problems

\begin{tabular}{|c|c|c|c|}
\hline & $\begin{array}{l}\text { Anxious } \\
\text { depressed }\end{array}$ & $\begin{array}{l}\text { Withdrawn } \\
\text { depressed }\end{array}$ & Somatization \\
\hline \multicolumn{4}{|l|}{ Actigraphy } \\
\hline TST & $-0.001(0.001)$ & $0.000(0.001)$ & $-0.001(0.001)^{\star}$ \\
\hline $\mathrm{COA}$ & $0.02(0.07)$ & $-0.12(0.07)$ & $-0.03(0.07)$ \\
\hline SOL & $0.001(0.001)$ & $0.001(0.001)$ & $0.002(0.001)^{*}$ \\
\hline COA & $0.02(0.07)$ & $-0.12(0.07)$ & $-0.02(0.07)$ \\
\hline SE & $0.001(0.003)$ & $0.000(0.003)$ & $-0.007(0.003)^{\star}$ \\
\hline $\mathrm{COA}$ & $0.02(0.07)$ & $-0.12(0.07)$ & $-0.04(0.07)$ \\
\hline WASO & 0.001 (0.002) & $-0.003(0.002)$ & 0.001 (0.002) \\
\hline COA & $0.02(0.07)$ & $-0.11(0.07)$ & $-0.03(0.07)$ \\
\hline \multicolumn{4}{|c|}{ Pediatric Sleep Questionnaire (parental) } \\
\hline $\begin{array}{l}\text { Sleep } \\
\text { difficulties }\end{array}$ & $0.14(0.06)^{*}$ & $0.22(0.06)^{\star \star \star}$ & $0.23(0.06)^{\star \star \star}$ \\
\hline COA & $-0.01(0.07)$ & $-0.13(0.06)^{*}$ & $-0.07(0.06)$ \\
\hline Sleepiness & $0.12(0.06)^{a}$ & $0.14(0.06)^{*}$ & $0.16(0.06)^{*}$ \\
\hline $\mathrm{COA}$ & $0.02(0.07)$ & $-0.12(0.06)$ & $-0.06(0.06)$ \\
\hline \multicolumn{4}{|c|}{ Child Behavior Checklist (parental) } \\
\hline Nightmare & $0.47(0.10)^{\star \star \star}$ & $0.44(0.10)^{\star \star \star}$ & $0.16(0.07)^{\star}$ \\
\hline COA & $0.14(0.07)$ & $-0.01(0.07)$ & $-0.04(0.06)$ \\
\hline $\begin{array}{l}\text { Nightmare } \\
\times \text { COA }\end{array}$ & $-0.30(0.13)^{*}$ & $-0.32(0.13)^{*}$ & \\
\hline Overtired & $0.04(0.10)$ & $0.26(0.09)^{\star \star}$ & $0.35(0.09)^{\star \star \star}$ \\
\hline $\mathrm{COA}$ & $0.03(0.07)$ & $-0.14(0.06)^{\star}$ & $-0.09(0.06)$ \\
\hline $\begin{array}{l}\text { Sleeps less } \\
\text { than most } \\
\text { children }\end{array}$ & $0.18(0.08)^{*}$ & $0.18(0.08)^{\star}$ & $0.16(0.08)^{*}$ \\
\hline COA & $0.02(0.07)$ & $-0.12(0.06)$ & $-0.05(0.07)$ \\
\hline $\begin{array}{l}\text { Sleeps more } \\
\text { than most } \\
\text { children }\end{array}$ & $0.09(0.12)$ & $-0.17(0.18)$ & $-0.35(0.18)$ \\
\hline $\mathrm{COA}$ & $0.03(0.07)$ & $-0.15(0.06)^{*}$ & $-0.11(0.06)$ \\
\hline $\begin{array}{l}\text { Sleeps more } \\
\times \text { COA }\end{array}$ & - & $0.59(0.22)^{\star \star}$ & $0.81(0.22)^{\star \star \star}$ \\
\hline $\begin{array}{l}\text { Trouble } \\
\text { sleeping }\end{array}$ & $0.26(0.07)^{\star \star \star}$ & $0.29(0.06)^{\star \star \star}$ & $0.19(0.07)^{\star \star}$ \\
\hline COA & $0.03(0.06)$ & $-0.12(0.06)^{\mathrm{a}}$ & $-0.05(0.06)$ \\
\hline
\end{tabular}

Multiple regression using sleep items and COA status to predict internalizing problems. Numbers are unstandardized betas and standard errors. Interaction terms are included if they are statistically significant.

TST, Total sleep time; SOL, sleep onset latency; SE, sleep efficiency or total time sleep/total time in bed; WASO, wake time after sleep onset.

${ }^{\mathrm{a}} p=0.05,{ }^{\star} p<0.05,{ }^{* *} p<0.01,{ }^{* *} p<0.001$.

$(0.08), p<0.05)$ (Fig. 1). Having nightmares was also significantly associated with being withdrawn depressed among non-COAs $(b=0.44(0.09), p<0.001)$, but the relationship was insignificant (though in the same direction) among COAs $(b=0.12(0.08), p=0.12)$. It should be noted that the 2 groups were not different on the likelihood of having nightmares. COAs who slept more were more likely than other COAs to have withdrawn/depressed problems $(b=0.41$ $(0.12), p<0.01)$ and somatic complaints $(b=0.46(0.13)$, $p<0.01)$. However, "sleeping more" did not predict withdrawn/depressed problems $(b=-0.17(0.19), p=0.38)$ or somatic complaints $(b=-0.35(0.18), p=0.07)$ in nonCOAs.

Regardless of COA status, multiple sleep measures were associated with internalizing problems. Actigraphy data showed that children with lower TST, longer SOL, and lower SE had more somatic complaints. PSQ data showed that children who had more sleep difficulties were higher on all 3 


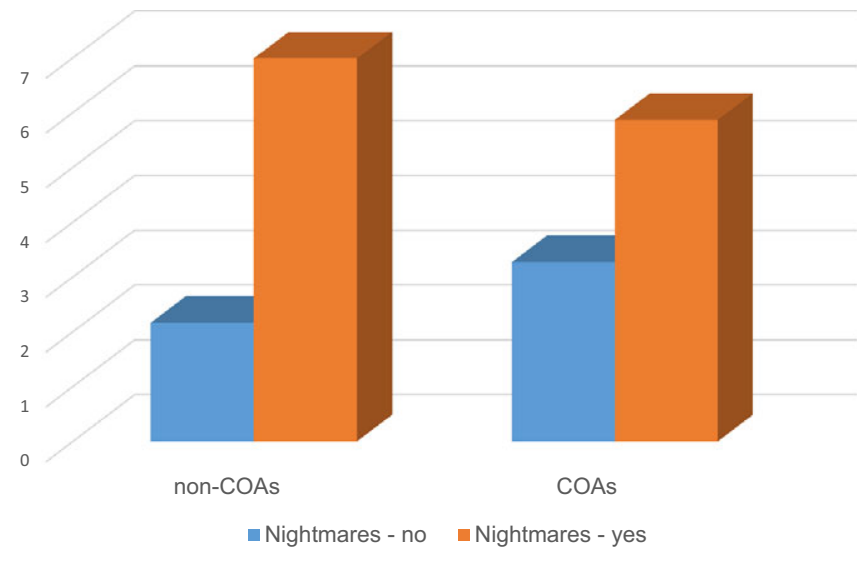

Fig. 1. Anxious-depressed problems among children with or without nightmares.

internalizing problems while children who were sleepy during daytime tended to be withdrawn/depressed and had somatic complaints. CBCL data revealed that children who were overtired, slept less than others, and had trouble sleeping were higher on all 3 internalizing problems.

The relationships between sleep parameters and externalizing problems were again mostly the same for COAs and nonCOAs (Table 3) with the following exceptions. Among nonCOAs, shorter TST predicted more rule-breaking behaviors $(b=-0.003(0.001), \quad p<0.01)$ and more impulsivity $(b=-0.004(0.002), p<0.05)$. However, TST was not significantly related to rule-breaking behaviors $(b=0.001(0.001)$, $p=0.07)$ or impulsivity $(b=0.00(0.001), p=1.00)$ among COAs (Fig. 2). There is also a significant interaction between sleeping more $\times$ COA status on rule-breaking behaviors $(b=0.43(0.22), p<0.05)$. Yet further analyses indicated that "sleeping more" was not significantly related to rule-breaking behaviors for either group.

Parental ratings of sleep significantly predicted externalizing problems. Children who had sleep difficulties (PSQ and CBCL) and nightmares (CBCL), regardless of their COA status, were more likely to break rules, be aggressive and impulsive compared with children with no sleep difficulties. Additionally, those who had daytime sleepiness (PSQ) were more likely to engage in rule-breaking behaviors while those who were overtired (CBCL) were more likely to be impulsive.

\section{Measurement Model}

Sleep Measures. Initially, we fitted 2 latent variables, separately for PSQ and CBCL items. Results indicated that both latent variables were highly correlated with one another $(r=0.92, p<0.001)$. We therefore combined the 2 variables into 1 latent variable, parental ratings. We tested whether all observed indicators of sleep loaded onto their corresponding latent variables. All loadings were statistically significant; that is, all observed variables were good indicators of the latent variables. Some observed items (i.e., WASO and sleeps
Table 3. Relations Among Sleep Measures, Children of Alcoholics (COA) Status, and Externalizing Problems

\begin{tabular}{|c|c|c|c|}
\hline & Rule-breaking & Aggression & Impulsivity \\
\hline \multicolumn{4}{|l|}{ Actigraphy } \\
\hline TST & $-0.003(0.002)^{\star}$ & $0.00(0.001)$ & $-0.004(0.002)^{*}$ \\
\hline $\mathrm{COA}$ & $-1.97(0.77)^{\star}$ & $0.04(0.08)$ & $-1.66(0.88)$ \\
\hline $\mathrm{TST} \times \mathrm{COA}$ & $0.005(0.002)^{\star \star}$ & - & $0.004(0.002)^{a}$ \\
\hline SOL & $0.00(0.001)$ & $0.001(0.001)$ & $0.001(0.001)$ \\
\hline $\mathrm{COA}$ & $0.11(0.06)$ & $0.04(0.08)$ & $0.07(0.07)$ \\
\hline SE & $0.004(0.003)$ & $-0.002(0.004)$ & $-0.001(0.003)$ \\
\hline COA & $0.12(0.07)$ & $0.04(0.08)$ & $0.07(0.07)$ \\
\hline WASO & $0.00(0.002)$ & $0.001(0.002)$ & $0.002(0.002)$ \\
\hline COA & $0.11(0.06)$ & $0.04(0.08)$ & $0.07(0.07)$ \\
\hline \multicolumn{4}{|c|}{ Pediatric Sleep Questionnaire (parental) } \\
\hline $\begin{array}{l}\text { Sleep } \\
\text { difficulties }\end{array}$ & $0.17(0.06)^{\star *}$ & $0.16(0.07)^{\star}$ & $0.16(0.06)^{\star}$ \\
\hline $\mathrm{COA}$ & $0.09(0.06)$ & $0.02(0.07)$ & $0.04(0.07)$ \\
\hline Sleepiness & $0.14(0.06)^{*}$ & $0.08(0.07)$ & $0.10(0.06)$ \\
\hline COA & $0.10(0.06)$ & $0.03(0.08)$ & $0.04(0.07)$ \\
\hline \multicolumn{4}{|c|}{ Child Behavior Checklist (parental) } \\
\hline Nightmare & $0.15(0.06)^{*}$ & $0.18(0.07)^{*}$ & $0.24(0.06)^{\star \star \star}$ \\
\hline COA & $0.11(0.06)$ & $0.03(0.07)$ & $0.06(0.06)$ \\
\hline Overtired & $0.11(0.09)$ & $0.14(0.11)$ & $0.22(0.09)^{\star}$ \\
\hline COA & $0.09(0.06)$ & $0.02(0.08)$ & $0.01(0.07)$ \\
\hline $\begin{array}{l}\text { Sleeps less } \\
\text { than most } \\
\text { children }\end{array}$ & $0.08(0.07)$ & $0.43(0.18)^{\star}$ & $0.14(0.08)$ \\
\hline $\mathrm{COA}$ & $0.10(0.06)$ & $0.10(0.08)$ & $0.06(0.07)$ \\
\hline $\begin{array}{l}\text { Sleeps less } \\
\times \text { COA }\end{array}$ & - & $-0.42(0.20)^{*}$ & - \\
\hline $\begin{array}{l}\text { Sleeps more } \\
\text { than most } \\
\text { children }\end{array}$ & $-0.22(0.18)$ & $0.23(0.13)$ & $0.12(0.12)$ \\
\hline $\mathrm{COA}$ & $0.08(0.06)$ & $0.04(0.07)$ & $0.05(0.07)$ \\
\hline $\begin{array}{l}\text { Sleeps more } \\
\times \text { COA }\end{array}$ & $0.43(0.22)^{*}$ & - & - \\
\hline $\begin{array}{l}\text { Trouble } \\
\text { sleeping }\end{array}$ & $0.16(0.06)^{\star}$ & $0.25(0.08)^{\star \star}$ & $0.23(0.07)^{\star \star}$ \\
\hline $\mathrm{COA}$ & $0.10(0.06)$ & $0.03(0.07)$ & $0.07(0.06)$ \\
\hline
\end{tabular}

Multiple regression using sleep items and COA status to predict externalizing problems. Numbers are unstandardized betas and standard errors. Interaction terms are included if they are statistically significant.

TST, total sleep time; SOL, sleep onset latency; SE, sleep efficiency or total time sleep/total time in bed; WASO, wake time after sleep onset.

${ }^{\mathrm{a}} p=0.05,{ }^{\star} p<0.05,{ }^{* \star} p<0.01,{ }^{* \star *} p<0.001$.

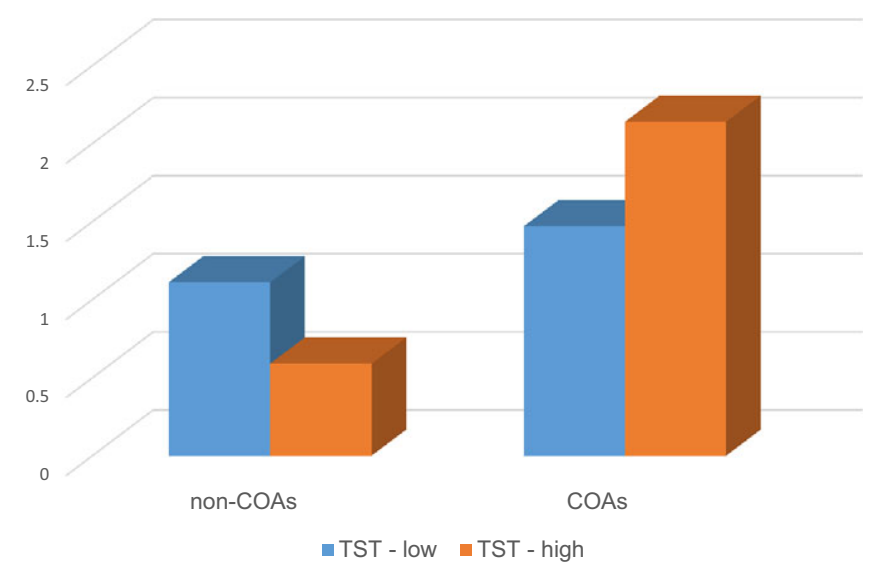

Fig. 2. Rule-breaking behaviors among children with low and high total sleep time (median split). 


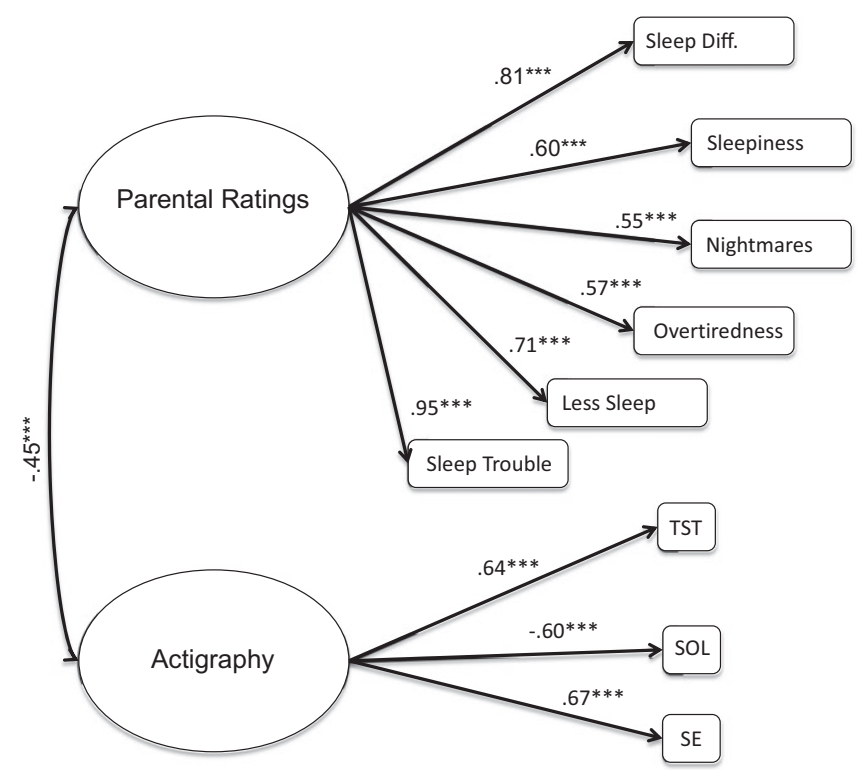

Fig. 3. Standardized factor loadings of and correlations among sleep measures. ${ }^{* * *} p<0.001$. TST, total sleep time; SOL, sleep onset latency; SE, sleep efficiency; Model fit: $\chi^{2}(26)=33.36, p=0.15$., $C F I=0.98$, $\mathrm{TLI}=0.97, \mathrm{RMSEA}=0.04$.

more than others) were highly correlated with other indicators on the same latent variables. Including them in the analyses led to model nonconvergence. They were dropped from the measurement model. The standardized factor loadings were presented in Fig. 3. Actigraphy variables (longer TST, shorter SOL, and higher SE) were negatively correlated with parental ratings of sleep difficulties $(r=-0.45, p<0.001)$. The overall fit indices indicate that the model fit the data well, $\chi^{2}(26)=33.36, \quad p=0.15, \quad$ CFI $=0.98, \quad$ TLI $=0.97$, RMSEA $=0.04$.

Behavioral Problems. We estimated 2 latent variables using CBCL subscales, internalizing and externalizing problems. Impulsivity was not used as an observed indicator of externalizing problems as it has items that overlap with rulebreaking behaviors and aggression. The standardized factor loadings were presented in Fig. 4. The 2 latent variables were significantly correlated with one another $(r=0.80$, $p<0.001)$. The overall model fit was excellent, $\chi^{2}(4)=2.25$, $p=0.69, \mathrm{CFI}=1.00, \mathrm{TLI}=1.03, \mathrm{RMSEA}=0.00$.

\section{Structural Model}

We examined whether actigraphy and parental ratings of sleep difficulties predicted behavioral problems in 2 separate models, 1 for internalizing and 1 for externalizing problems. We also tested whether there were any differences between COAs and non-COAs in these relationships. Parental ratings were a significant predictor of internalizing problems (Fig. 5). We tested whether these relationships were the same in both groups. Chi-square difference tests showed that there were no significant group differences (parental ratings:

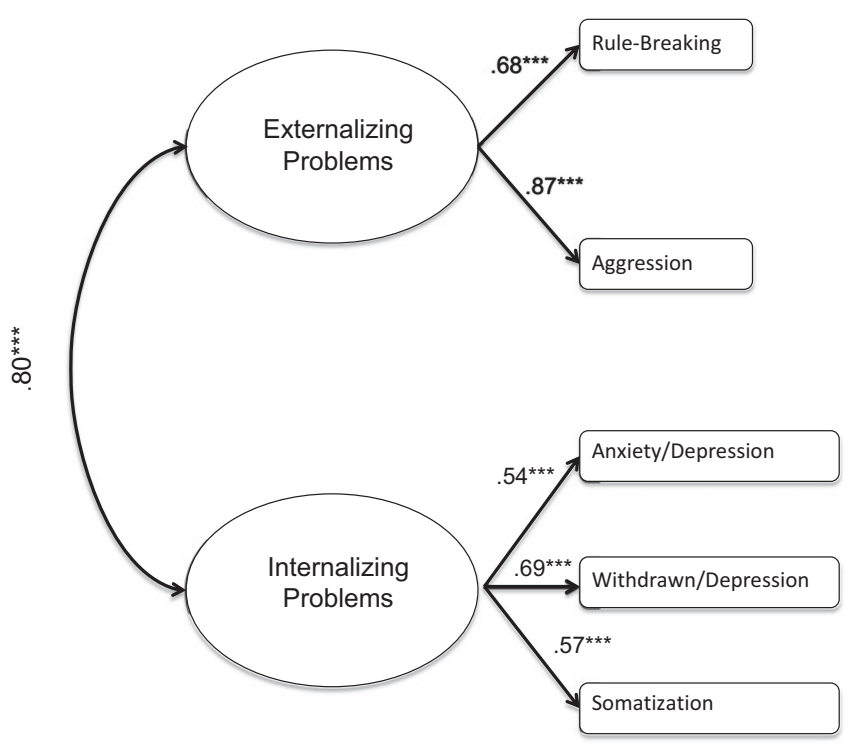

Fig. 4. Standardized factor loadings of and correlations among behavioral measures. Numbers listed are standardized betas and correlations. ${ }_{* \star \star} p<0.001$. Model fit: $\chi^{2}(4)=2.25, p=0.69, \mathrm{CFI}=1.00, \mathrm{TLI}=1.03$, RMSEA $=0.00$.

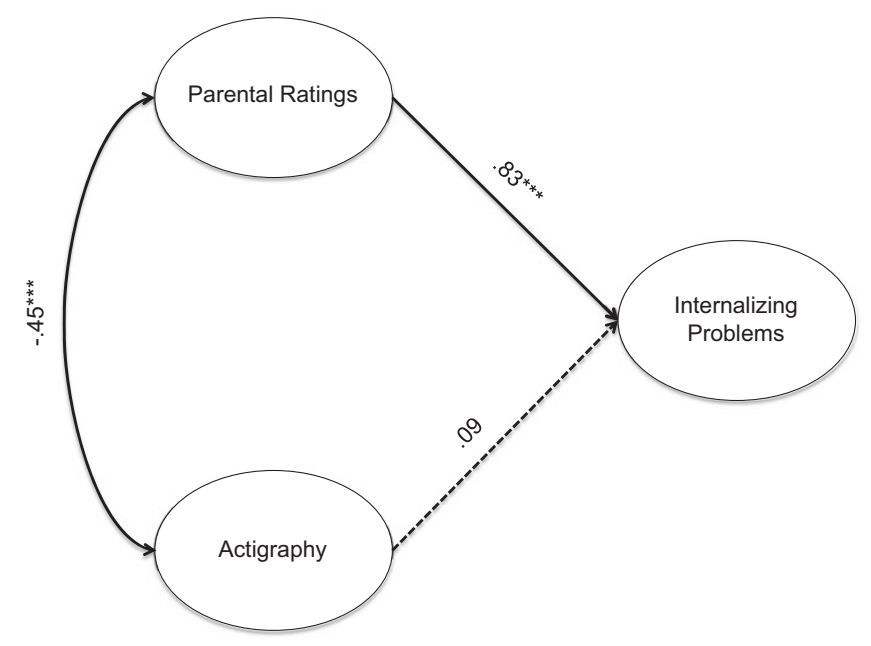

Fig. 5. Relationships between sleep measures and internalizing problems. Numbers listed are standardized betas and correlations. ${ }^{\star * *} p<0.001$. Dotted lines are nonsignificant paths. Model fit: $\chi^{2}(51)=67.98, p=0.06, \mathrm{CFI}=0.95, \mathrm{TLI}=0.94, \mathrm{RMSEA}=0.04$.

$\chi^{2}(1)=0.03, p=0.86$; actigraphy: $\left.\chi^{2}(1)=1.65, p=0.20\right)$. As there were no group differences, the 2 groups were collapsed and the analyses were carried out on the whole sample. Participants whose parents thought they had sleep difficulties had more internalizing problems $(\beta=0.83$, $p<0.001)$. In contrast, actigraphy measures had no relationship with internalizing problems $(\beta=0.09, p=0.46)$. This model fit the data very well, $\chi^{2}(51)=67.98, p=0.06$, $\mathrm{CFI}=0.95, \mathrm{TLI}=0.94, \mathrm{RMSEA}=0.04$.

There were also no significant group differences on the relationship between any sleep variables and externalizing problems (parental ratings: $\chi^{2}(1)=0.03, \quad p=0.86$; 


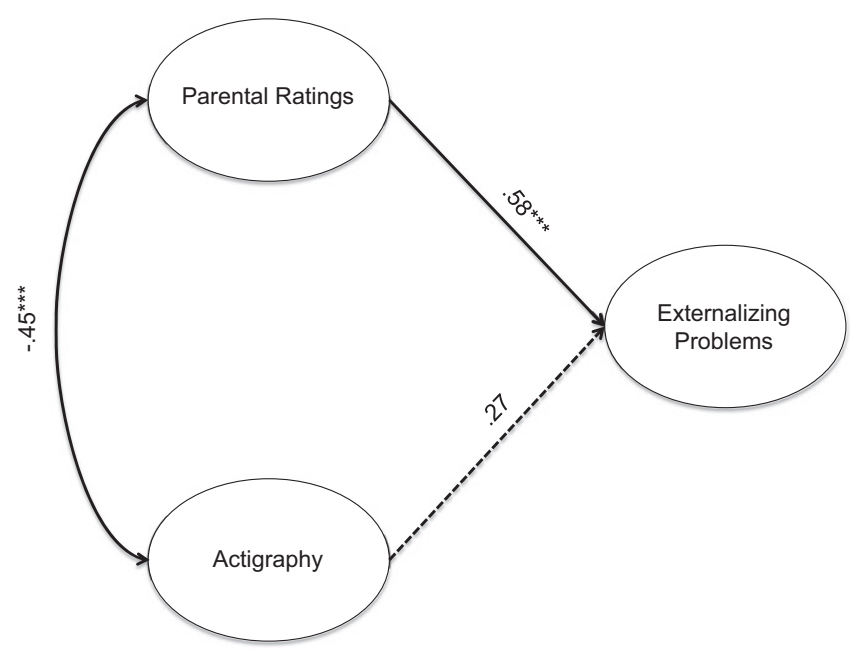

Fig. 6. Relationships between sleep measures and externalizing problems. Numbers listed are standardized betas and correlations. ${ }^{* \star *} p<0.001$. Dotted lines are nonsignificant paths. Model fit: $\chi^{2}(41)=45.98, p=0.27, \mathrm{CFI}=0.99, \mathrm{TLI}=0.98, \mathrm{RMSEA}=0.03$.

actigraphy: $\left.\chi^{2}(1)=1.94, p=0.16\right)$. Only parental ratings predicted externalizing problems $(\beta=0.58, \quad p<0.001)$ (Fig. 6). Actigraphy measures had no significant relationship with externalizing problems $(\beta=0.27, p=0.10)$. Overall model fit was again excellent, $\chi^{2}(41)=45.98, p=0.27$, $\mathrm{CFI}=0.99, \mathrm{TLI}=0.98, \mathrm{RMSEA}=0.03$.

\section{DISCUSSION}

We compared COAs and non-COAs on multiple sleep measures and behavioral problems. We also examined whether the relationships between different sleep measures and behavioral problems were different between the 2 groups. Although the 2 hypotheses were only partially supported, this study added to the growing literature by corroborating past research findings that young COAs and nonCOAs had minimal differences on sleep measures. It also extended previous research by identifying how COA status moderated the relationship between several sleep measures and behavioral problems, a question that has not been directly addressed by previous research.

Research on sleep among COAs and non-COAs shows that the 2 groups generally do not differ except for differences on TST (Conroy et al., 2015; Hairston et al., 2016) and on lower delta and sigma power during sleep (Tarokh and Carskadon, 2010; Tarokh et al., 2012). The hypothesis that COAs would show minimal differences on sleep measures compared with non-COAs was supported. COAs and nonCOAs were not different on sleep measures except parental ratings of "overtiredness for no good reasons." While many factors other than sleep could cause overtiredness, this characteristic was associated with having trouble sleeping $\left(\chi^{2}(1)=5.49, p<0.05\right)$ and "sleeping more than other children" in this study $\left(\chi^{2}(1)=10.42, p<0.001\right)$. The relationship between overtiredness and trouble sleeping has also been reported in other samples (Wong et al., 2009, 2010). Previous research has reported lower spectral power during sleep among COAs compared with non-COAs, suggesting that certain circuits responsible for "protecting" sleep may be impaired (Tarokh and Carskadon, 2009; Tarokh et al., 2012). This impairment could have led to micro-arousals in sleep and overtiredness. Other factors not reported in this study such as regularity of sleep-wake patterns (Hasler et al., 2015), chaotic and noisy home environments (Brown and Low, 2008), and presence of family conflict (El-Sheikh et al., 2015) may also affect sleep and tiredness. Future studies could examine how these factors affect overtiredness among COAs. Parental ratings of overtiredness were associated with behavioral problems in this study. Previous research indicated that maternal ratings of overtiredness longitudinally predicted early onset of alcohol and other drug use (Wong et al., 2004, 2009), as well as substance-related problems (Wong et al., 2010). Overtiredness in daily activities appears to be an important risk pathway for subsequent problematic alcohol involvement. Our study suggests that this pathway may be especially salient for COAs.

The hypothesis that sleep parameters and behavioral problems would have a stronger relationship among COAs than non-COAs was mostly unsupported. SEM models showed no differences in the relationships between latent variables of sleep measures and either internalizing or externalizing problems among COAs and non-COAs. In regression models, the relationships between individual sleep items and behavioral problems were largely the same for both COAs and nonCOAs, with a few notable exceptions. The presence of nightmares was more strongly associated with anxiety/depression and withdrawn/depression for non-COAs than COAs, even though the relationships were in the same direction for both groups. Moreover, nightmares were significantly associated with rule-breaking, aggression, and impulsivity for all participants, regardless of COA status. A cross-sectional study reported that frequent nightmares (having nightmares at least once a week) was associated with hyperactivity and temper outbursts in a community sample of Chinese children (Li et al., 2011). Longitudinal data revealed an association between nightmares and anxiety (Simard et al., 2008), as well as difficult temperament (Simard et al., 2008) and emotional symptoms (Schredl et al., 2009) in children. The consistency of our results to previous research highlights the effects of nightmares in children's behavior and the need of treatment among those with persistent nightmares.

Among non-COAs, parental rating of sleeping less was associated with aggression and shorter TST was associated with more rule-breaking and impulsivity. These findings are consistent with past research showing that less sleep and sleep difficulties are associated with behavioral problems (Gregory and Sadeh, 2012). National polls indicated that as much as $27 \%$ of school-aged children (National Sleep Foundation, 2004) and $45 \%$ of adolescents did not get enough sleep (National Sleep Foundation, 2006). The high prevalence of insufficient sleep and its association with behavioral 
problems underscore the importance of helping our nation's youth to practice sleep hygiene and prioritize sleep in their daily schedule.

Among COAs, parental rating of sleeping more was associated with somatization and withdrawal. To our knowledge, this is the first study to report such differences. Previous research indicated that COAs had lower spectral power in their sleep than non-COAs (Tarokh and Carskadon, 2010; Tarokh et al., 2012). Could COAs be less restful in their sleep, which led to overtiredness and sleeping more? Future studies could address this question by examining the relationship between sleep micro-architecture and behavioral problems among these 2 groups of children.

Parental ratings of sleep difficulties and having trouble sleeping are related to both internalizing and externalizing problems. These problems predict psychopathology in adolescence and adulthood. As we present cross-sectional data here, we could not ascertain the temporal relationship between sleep difficulties and behavioral problems. Longitudinal studies show that sleep problems predicted subsequent behavioral and emotional problems (Gregory and Sadeh, 2012; Gregory et al., 2005). The relationship between sleep and behavioral problems is probably reciprocal (Wang et al., 2016). While sleep difficulties may be a risk factor for behavioral problems in children and adolescents, behavioral problems may also affect sleep, especially when those problems create difficulties in interpersonal relations and school work. Prospective studies examining the developmental trajectories of sleep and behavioral problems simultaneously over a longer time frame will shed light on how they influence each other over time. The association between sleep difficulties and behavioral problems has an important implication. Prevention and treatment programs aiming at either problem should inform children/adolescents and their parents of this relationship and be prepared to offer consultation or treatment for both problems.

The hypothesis that COAs had more behavioral problems than non-COAs was not supported. Previous studies report that COAs tend to have more internalizing and externalizing problems than non-COAs (Eiden et al., 2007; Hussong et al., 2008a). However, multiple factors such as children's age and developmental stage, the subtype of parental alcoholism, the timing of parental alcohol diagnoses, and alcohol-related consequences affect the manifestation and severity of these problems (Hussong et al., 2008b; Zucker, 2006). Our sample was still relatively young ( 8 to 12 years old) when they took part in this study. More behavioral problems among COAs could develop as they get older. We did not collect data on alcoholism subtype. However, there is limited information on timing of parental AUD, that is, whether parents have AUD in the last 12 months. These data are still being processed. We will analyze these data as they become available to find out whether parental AUD in the last 12 months is a better predictor of offspring behavioral problems than lifetime AUD, the criteria used to classify COAs in this study.
This study has several limitations. The cross-sectional data presented here did not provide any information on the temporal relationship between sleep and behavioral problem. Additionally, there was no experimental manipulation of either sleep or behavioral problems. The causal relationship between these 2 variables remains unknown. No PSG data were presented in this study. Assessment of brain activity during sleep is considered the gold standard of sleep measurement. We will examine the relationship between PSG and behavioral problems when PSG data become available. Lack of data on circadian sleep-wake cycle on weekdays versus weekends is another limitation. Irregular circadian rhythm may contribute to daytime fatigue. Environmental stressors related to parental alcohol problems such as chaotic home environment and noisy surroundings may affect both sleep and behavioral problems. We did not provide any data on environmental stressors in this study. It remains to be seen whether findings reported here can be replicated in studies with information on circadian rhythm and environmental stressors. This study relied on parents to provide information about sleep and behavioral problems. It is important to note that parents with alcohol problems may be biased in the ratings. Some participating parents do not have a history of alcohol problems so their responses may be different from those who have a positive lifetime history. Another limitation is that we did not control for the parental lifetime use of substances other than alcohol or prenatal exposure to these drugs, which may affect the pattern of findings reported here. Last, the sample size is relatively small; therefore, the power to detect statistically significant interaction effects may be inadequate.

In conclusion, sleep duration and difficulties appear to be general risk factors for behavioral problems in both COAs and non-COAs, yet the relationships between some sleep parameters and behavioral problems are different between the 2 groups. Examining the relationship between sleep micro-architecture and behavioral problems may reveal mechanisms that explain such differences.

\section{ACKNOWLEDGMENTS}

The work presented here was supported in part by a research grant from the National Institute on Alcohol Abuse and Alcoholism and National Institute of General Medical Sciences (R01 AA020364). However, the funding agencies had no further role in the study design, planning, data collection, analysis and interpretation of data, and writing of the report or the decision to submit the manuscript for publication. The authors are responsible for the opinions expressed in this manuscript. We thank all participants and the research staff of this study. The authors have no conflict of interest to report.

\section{REFERENCES}

Acebo C, Sadeh A, Seifer R, Tzischinsky O, Wolfson AR, Hafer A, Carskadon MA (1999) Estimating sleep patterns with activity monitoring in 
children and adolescents: how many nights are necessary for reliable measures? Sleep 22:95-103.

Achenbach T (1991) Manual for the Child Behavior Checklist/4-18 and 1991 Profile. University of Vermont Department of Psychiatry, Burlington, VT.

American Psychiatric Association (2000) Diagnostic and Statistical Manual of Mental Disorders. 4th ed., text revision. American Psychiatric Association, Washington DC.

Ancoli-Israel S, Cole R, Alessi C, Chambers M, Moorcroft W, Pollak CP (2003) The role of actigraphy in the study of sleep and circadian rhythms. Sleep 26:342-392.

Bentler PM (1990) Fit indexes, Lagrange multipliers, constraint changes and incomplete data in structural models. Multivariate Behav Res 25:169-172.

Bentler PM, Bonett DG (1980) Significance tests and goodness of fit in the analysis of covariance structures. Psychol Bull 88:588-606.

Brown ED, Low CM (2008) Chaotic living conditions and sleep problems associated with children's responses to academic challenge. J Fam Psychol 22:920-923.

Chervin RD, Hedger KM, Dillon JE, Pituch KJ (2000) Pediatric Sleep Questionnaire (PSQ): validity and reliability of scales for sleep-disordered breathing, snoring, sleepiness, and behavioral problems. Sleep Med 1:2132.

Conroy DA, Hairston IS, Zucker RA, Heitzeg MM (2015) Sleep patterns in children of alcoholics and the relationship with parental reports. Austin $\mathrm{J}$ Sleep Disord 2:1009.

Eiden RD, Edwards EP, Leonard KE (2007) A conceptual model for the development of externalizing behavior problems among kindergarten children of alcoholic families: role of parenting and children's self-regulation. Dev Psychol 43:1187-1201.

Eiden RD, Molnar DS, Colder C, Edwards EP, Leonard KE (2009) A conceptual model predicting internalizing problems in middle childhood among children of alcoholic and nonalcoholic fathers: the role of marital aggression. J Stud Alcohol Drugs 70:741-750.

El-Sheikh M, Hinnant JB, Erath SA (2015) Sleep and development: advancing theory and research: VI. Marital conflict, vagal regulation, and children's sleep: a longitudinal investigation. Monogr Soc Res Child Dev 80:89-106.

Gregory AM, Caspi A, Eley TC, Moffitt TE, O'Connor TG, Poulton R (2005) Prospective longitudinal associations between persistent sleep problems in childhood and anxiety and depression disorders in adulthood. $\mathbf{J}$ Abnorm Child Psychol 33:157-163.

Gregory AM, O'Connor TG (2002) Sleep problems in childhood: a longitudinal study of developmental change and association with behavioral problems. J Am Acad Child Adolesc Psychiatry 41:964-971.

Gregory AM, Sadeh A (2012) Sleep, emotional and behavioral difficulties in children and adolescents. Sleep Med Rev 16:129-136.

Hairston IS, Conroy DA, Heitzeg MM, Akbar NZ, Brower KJ, Zucker RA (2016) Sleep mediates the link between resiliency and behavioural problems in children at high and low risk for alcoholism. J Sleep Res 25:341-349.

Hasler BP, Soehner AM, Clark DB (2015) Sleep and circadian contributions to adolescent alcohol use disorder. Alcohol 49:377-387.

$\mathrm{Hu}$ L, Bentler PM (1999) Cutoff criteria for fit indexes in covariance structure analysis: conventional criteria versus new alternatives. Struct Equ Modeling 6:1-55.

Hussong AM, Cai L, Curran PJ, Flora DB, Chassin LA, Zucker RA (2008a) Disaggregating the distal, proximal, and time-varying effects of parent alcoholism on children's internalizing symptoms. J Abnorm Child Psychol 36:335-346.

Hussong AM, Flora DB, Curran PJ, Chassin LA, Zucker RA (2008b) Defining risk heterogeneity for internalizing symptoms among children of alcoholic parents. Dev Psychopathol 20:165-193.

Hussong AM, Jones DJ, Stein GL, Baucom DH, Boeding S (2011) An internalizing pathway to alcohol use and disorder. Psychol Addict Behav 25:390-404.

Li SX, Yu MWM, Lam SP, Zhang J, Li AM, Lai KYC, Wing YK (2011) Frequent nightmares in children: familial aggregation and associations with parent-reported behavioral and mood problems. Sleep 34:487-493.
Maasalo K, Fontell T, Wessman J, Aronen ET (2016) Sleep and behavioural problems associate with low mood in Finnish children aged 4-12 years: an epidemiological study. Child Adolesc Psychiatry Mental Health 10:37.

Meldrum RC, Young JTN, Hay C, Flexon JL (2012) Does self-control influence maternal attachment? A reciprocal effects analysis from early childhood through middle adolescence. J Quant Criminol 28:673-699.

Meyers JL, Shmulewitz D, Elliott JC, Thompson RG, Aharonovich E, Spivak B, Weizman A, Frisch A, Grant BF, Hasin DS (2014) Parental alcohol history differentially predicts offspring disorders in distinct subgroups in Israel. J Stud Alcohol Drugs 75:859-869.

Moore M, Kirchner HL, Drotar D, Johnson N, Rosen C, Ancoli-Israel S, Redline S (2009) Relationships among sleepiness, sleep time, and psychological functioning in adolescents. J Pediatr Psychol 34:1175-1183.

National Sleep Foundation (2004) Sleep in American Poll: Children and Sleep. National Sleep Foundation, Washington, DC.

National Sleep Foundation (2006) Sleep in America Poll: Teens and Seep. National Sleep Foundation, Washington, DC.

Rychtarik RG, McGillicuddy NB (2005) Coping skills training and 12-step facilitation for women whose partner has alcoholism: effects on depression, the partner's drinking, and partner physical violence. J Consult Clin Psychol 73:249-261.

Sadeh A (2015) Sleep and development: advancing theory and research: III. Sleep assessment methods. Monogr Soc Res Child Dev 80:33-48.

Sadeh A, Gruber R, Raviv A (2002) Sleep, neurobehavioral functioning, and behavior problems in school-age children. Child Dev 73:405-417.

Schredl M, Fricke-Oerkermann L, Mitschke A, Wiater A, Lehmkuhl G (2009) Longitudinal study of nightmares in children: stability and effect of emotional symptoms. Child Psychiatry Hum Dev 40:439-449.

Selzer ML (1971) The Michigan Alcoholism Screening Test: the quest for a new diagnostic instrument. Am J Psychiatry 127:1653-1658.

Selzer ML, Barton E (1977) The drunken driver: a psychosocial study. Drug Alcohol Depend 2:239-253.

Selzer ML, Vanosdall FE, Chapman M (1971) Alcoholism in a problem driver group: a field trial of the Michigan Alcoholism Screening Test (MAST). J Saf Res 3:176-181.

Sheehan DV, Lecrubier Y, Sheehan KH, Amorim P, Janavs J, Weiller E, Hergueta T, Baker R, Dunbar GC (1998) The Mini-International Neuropsychiatric Interview (M.I.N.I.): the development and validation of a structured diagnostic psychiatric interview for DSM-IV and ICD-10. J Clin Psychiatry 59(Suppl 20):22-33.

Sheehan DV, Lecrubier Y, Sheehan KH, Janavs J, Weiller E, Keskiner A, Schinka J, Knapp E, Sheehan MF, Dunbar GC (1997) The validity of the Mini International Neuropsychiatric Interview (MINI) according to the SCID-P and its reliability. Eur Psychiatry 12:232-241.

Sheehan DV, Sheehan KH, Shytle RD, Janavs J, Bannon Y, Rogers JE, Milo KM, Stock SL, Wilkinson B (2010) Reliability and validity of the Mini International Neuropsychiatric Interview for Children and Adolescents (MINI-KID). J Clin Psychiatry 71:313-326.

Simard V, Nielsen TA, Tremblay RE, Boivin M, Montplaisir JY (2008) Longitudinal study of bad dreams in preschool-aged children: prevalence, demographic correlates, risk and protective factors. Sleep 31:62-70.

Steiger JH, Lind JC (1980) Statistically based tests for the number of common factors, in Annual Meeting of the Psychometric Society, 758:424 453, Iowa City, IA.

Tarokh L, Carskadon MA (2009) Sleep electroencephalogram in children with a parental history of alcohol abuse/dependence. J Sleep Res 19:165174.

Tarokh L, Carskadon MA (2010) Sleep electroencephalogram in children with a parental history of alcohol abuse dependence. J Sleep Res 19:165174.

Tarokh L, Van RE, Acebo C, LeBourgeois M, Seifer R, Fallone G, Carskadon MA (2012) Adolescence and parental history of alcoholism: insights from the sleep EEG. Alcohol Clin Exp Res 36:1530-1541.

Thomas EJ, Santa C, Bronson D, Oyserman D (1986) Unilateral family therapy with the spouses of alcoholics. J Soc Serv Res 10:145-162.

Tucker LR, Lewis C (1973) A reliability coefficient for maximum likelihood factor analysis. Psychometrika 38:1-10. 
Wang B, Isensee C, Becker A, Wong J, Eastwood PR, Huang R-C, Runions KC, Stewart RM, Meyer T, Brüni LG, Zepf FD, Rothenberger A (2016) Developmental trajectories of sleep problems from childhood to adolescence both predict and are predicted by emotional and behavioral problems. Front Psychol 7:1874.

Wong MM, Brower KJ, Fitzgerald HE, Zucker RA (2004) Sleep problems in early childhood and early onset of alcohol and other drug use in adolescence. Alcohol Clin Exp Res 28:578-587.

Wong MM, Brower KJ, Nigg JT, Zucker RA (2010) Childhood sleep problems, response inhibition, and alcohol and drug outcomes in adolescence and young adulthood. Alcohol Clin Exp Res 34:1033-1044.
Wong MM, Brower KJ, Zucker RA (2009) Childhood sleep problems, early onset of substance use and behavioral problems in adolescence. Sleep Med 10:787-796.

Zucker RA (2006) Alcohol use and the alcohol use disorders: a developmental-biopsychosocial systems formulation covering the life course, in Developmental Psychopathology: Risk, Disorder, and Adaptation, 2nd ed., Vol. 3 (Cicchetti D, Cohen DJ eds), pp 620-656. John Wiley \& Sons Inc, Hoboken, NJ.

Zucker RA, Heitzeg MM, Nigg JT (2011) Parsing the undercontrol-disinhibition pathway to substance use disorders: a multilevel developmental problem. Child Dev Perspect 5:248-255. 